\title{
Consumo e Digestibilidade Aparente em Bezerros da Raça Holandesa Alimentados com Dietas Contendo Diferentes Níveis de Volumoso ${ }^{1}$
}

\section{Ricardo Dias Signoretti ${ }^{2}$, José Fernando Coelho da Silva ${ }^{3}$, Sebastião de Campos Valadares Filho $^{3}$, José Carlos Pereira ${ }^{3}$, Paulo Roberto Cecon ${ }^{4}$, Augusto César de Queiroz ${ }^{3}$, Gherman Garcia Leal de Araújo ${ }^{5}$, Giselle Mariano Lessa de Assis ${ }^{6}$}

\begin{abstract}
RESUMO - O objetivo deste trabalho foi avaliar o efeito de diferentes níveis de volumoso nas dietas sobre os consumos e as digestibilidades aparentes de matéria seca (MS), matéria orgânica (MO), proteína bruta (PB), extrato etéreo (EE), fibra em detergente neutro (FDN), carboidratos totais (CHOT) e energia bruta (EB) e sobre os consumos de nutrientes digestíveis totais (NDT). Trinta e cinco bezerros da raça Holandesa puros por cruzamento, não-castrados, com idade média de 60 dias e peso vivo inicial de $78 \mathrm{~kg}$, foram distribuídos em delineamento inteiramente casualizado, com nove repetições por dieta, exceto para a dieta com $10 \%$ de volumoso, com oito repetições. Os animais foram alimentados à vontade com dietas contendo níveis de 10, 25, 40 e 55\% de volumoso, na base da MS, usando-se feno de capim coast-cross (Cynodon dactylon), fubá de milho e farelo de soja, os quais constituíram dietas com aproximadamente $16 \%$ de PB. O óxido crômico foi usado para obtenção das estimativas dos fluxos de MS fecal. Os carboidratos totais foram obtidos por $100-(\% \mathrm{~PB}+\% \mathrm{EE}+\%$ Cinzas $)$. O consumo de NDT foi obtido por (cPB - PBf $)+2,25$ (cEE - EEf $)+(\mathrm{cCHOT}-\mathrm{CHOTf})$, em que c significa consumo e $\mathrm{f}$, excreção fecal. Não houve efeito dos níveis de volumoso nas dietas sobre os consumos de MS e MO (kg/ dia, \% PV e g/kg ${ }^{0,75}$ ) e de PB e CHOT (kg/dia e \% PV). O consumo de FDN (kg/dia, \%PV e g/kg ${ }^{0,75}$ ) aumentou, enquanto o consumo de EE e NDT (em kg/dia e \%PV) reduziu linearmente em função dos níveis de volumoso na dieta. Houve efeito linear decrescente sobre as digestibilidades aparentes de MS, MO, PB, EE, CHOT e EB, em função do aumento dos níveis de volumoso nas dietas, enquanto a digestibilidade aparente da FDN não foi influenciada. Os consumos de EE, FDN e NDT e as digestibilidades aparentes de MS, MO, EE, $\mathrm{PB}, \mathrm{CHOT}$ e EB foram influenciados pelos níveis de volumoso nas dietas.
\end{abstract}

Palavras-chave: bezerro holandês, digestibilidade, ingestão, nível de volumoso

\section{Intake and Apparent Digestibility Coefficients in Calves Fed Diets with Different Forage Levels}

\begin{abstract}
This work was to evaluate the effect of different forage levels in the diet on the intake and apparent digestibility of dry matter (DM), organic matter (OM), crude protein (CP), ether extract (EE), neutral detergent fiber (NDF), total carbohydrate (CHO), gross energy (GE) and total digestible nutrients (TDN). Thirty five pure Holstein bull calves, 60 days old with initial average live weight ( $\mathrm{LW})$ of $78 \mathrm{~kg}$, were allotted in a completely randomized experimental design with nine replications per diet, except for the $10 \%$ forage diet, with eight replicates. The animals were ad libitum fed with diets contained $10 ; 25 ; 40$; and $55 \%$ of forage, on the DM basis, using chopped coast-cross (Cynodon dactylon) grass, ground corn and soybean meal, which constitute diets with approximately $16 \% \mathrm{CP}$. The chromium oxide was used to obtain the fecal DM excretion estimates. The total carbohydrate was calculated as $100-(\% \mathrm{CP}+\% \mathrm{EE}+\%$ ash $)$. The TDN was calculated as $(\mathrm{cCP}-\mathrm{fCP})+2.25(\mathrm{cEE}-\mathrm{fEE})+(\mathrm{cCHO}-\mathrm{fCHO})$, where $\mathrm{c}$ means intake and $\mathrm{f}$ fecal excretion. There were no effects of forage level in the diet on DM and OM intakes (kg/day, \% LW and $\left.\mathrm{g} / \mathrm{kg} \cdot{ }^{75}\right)$ and $\mathrm{CP}$ and $\mathrm{CHO}\left(\mathrm{kg} /\right.$ day and \% LW). The NDF intake $\left(\mathrm{kg} / \mathrm{day}, \% \mathrm{LW}\right.$ and $\left.\mathrm{g} / \mathrm{kg} \cdot{ }^{75}\right)$ increased while the EE and TDN intake decreased linearly, in function of the increased forage level in the diet. The apparent digesitibilities of DM, OM, CP, EE, CHO and GE decreased linearly in function of increased level of forage in the diet, while the NDF apparent digestibility was not affected. The intakes of EE, NDF and TDN and the apparent digestibility coefficients of DM, OM, EE, CP, CHO and GE were affected by forage level in the diet.
\end{abstract}

Key Words: Holstein calf, digestibility, feed intake, forage level

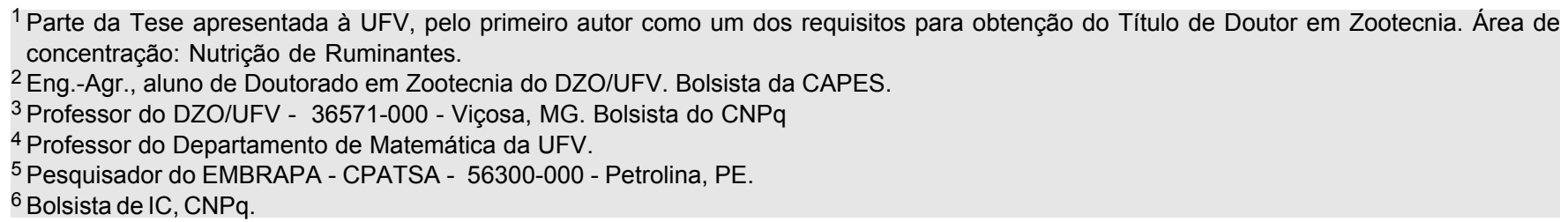




\section{Introdução}

Para a formulação de dieta para bovinos em crescimento, ao início do confinamento, devem ser considerados os seguintes fatores dietéticos: o consumo de matéria seca esperado, a proporção de volumoso e concentrado, o nível e a fonte de proteína suplementar e a digestibilidade dos componentes dietéticos (FLUHARTY et al., 1994). Além disso, outro ponto relevante é a suplementação adequada de macro e microelementos minerais e vitamínicos, principalmente vitaminas A, D e E (NRC,1989).

A ingestão de matéria seca é o fator mais importante que determina a performance animal, pois é o primeiro ponto determinante do ingresso de nutrientes, principalmente energia e proteína, necessários ao atendimento das exigências de mantença e produção animal (NOLLER et al., 1996). Contudo, a predição do consumo é o ponto crítico de todos os métodos e modelos atuais de formulação de dietas (ILLIUS e JESSOP, 1996).

O consumo voluntário é, por definição, a quantidade máxima de matéria seca que um animal espontaneamente ingere, enquanto a capacidade de um alimento ser ingerido depende da ação de vários fatores que interagem em diferentes situações de alimentação, comportamento animal e meio ambiente (THIAGO e GILL, 1990).

Inúmeros fatores complexos atuam nas sensações de fome e saciedade e na inter-relação dos mesmos. O consumo é função do animal (peso vivo, nível de produção, variação no peso vivo, individualidade animal, depósitos de gordura prévios, fase de crescimento, sexo, idade, tamanho do animal, dentre outros), do alimento (FDN efetiva, capacidade de enchimento, densidade energética, necessidade de mastigação, composição, forma física, balanço de nutrientes: principalmente, energia e proteína, digestibilidade, dentre outros), das condições de manejo da alimentação (disponibilidade de alimento, espaço no cocho, tempo de acesso ao alimento, freqüência de alimentação, seleção da dieta, dentre outros), das condições ambientais (temperatura e umidade relativa do ar, fotoperíodo, estação do ano, dentre outros), além do manejo diário e das causas sociais (ARC,1980; THIAGO e GILL, 1990; MERTENS, 1992; MERTENS, 1994; FORBES, 1996; e ILLIUS e JESSOP, 1996). Entretanto, os fatores que influem no consumo e no estímulo dos mecanismos que o regulam não são completamente entendidos (MERTENS, 1994).
O consumo de alimentos volumosos é positivamente relacionado à taxa ou extensão da digestão no rúmen (teoria física), que tem sido sustentado pela descoberta de receptores na parede ruminal sensíveis à expansão e ao contato e pelo fato de ocorrer redução no consumo, quando a capacidade do rúmen é diminuída (ALLEN, 1996; FORBES, 1996). A teoria quimiostática baseia-se na elevação de produtos metabólicos no rúmen (receptores sensíveis aos ácidos graxos de cadeia curta) ou no sangue após alimentação, que estimulam receptores quimicamente sensíveis, que, por sua vez, ativam o sistema nervoso central responsável pelo estado de saciedade (ILLIUS e JESSOP, 1996).

O principal estímulo para consumo de alimentos é a necessidade energética do animal, mas este é modificado pela integração dos efeitos da dieta com funções fisiológicas do animal. Considerando este fato, a quantidade de alimentos ingeridos em ciclo alimentar de 24 horas representa o somatório das diversas refeições que ocorreram durante o ciclo alimentar e, seguindo este mesmo raciocínio, os fatores que controlam o consumo diário serão também o resultado do somatório dos fatores envolvidos no término de cada refeição individual. Como a importância do mecanismo físico e fisiológico no controle do consumo parece alternar-se dentro de um ciclo alimentar, é possível que o mecanismo dominante na cessação de refeição individual seja diferente daquele que controla o consumo diário, principalmente com dietas de alta qualidade (GILL et al., 1987).

O consumo voluntário de MS é altamente relacionado ao conteúdo de FDN do alimento e da dieta, porque a fermentação e a passagem de FDN pelo rúmen-retículo são mais lentas que outros constituintes dietéticos, tendo grande efeito no enchimento e sobre o tempo de permanência comparado com os componentes não-fibrosos do alimento (VAN SOEST, 1965). Contudo, muitos outros fatores influenciam o enchimento, incluindo o tamanho de partícula, a freqüência de mastigação e a fragilidade efetiva da partícula, a fração indigestível da FDN, a taxa de fermentação da FDN potencialmente digestível e as características das contrações reticular (ALLEN,1996). Quando o volume da dieta é o fator limitante, os animais não são capazes de ingerir quantidades suficientes de MS para suprir suas necessidades energéticas, o que implica em menor produção. Por outro lado, a ingestão e a digestibilidade são negativamente correlacionadas, quando se trata de dietas de alta qualidade, em que a fração fibrosa é pequena e, 
provavelmente, não influencia a ingestão, a qual será controlada pela exigência energética do animal.

RODRIGUEZ et al. (1996) verificaram maiores consumos de MS, MO e PB para rações com maior teor de concentrado, em animais da raça Holandesa, com idade aproximada de 1 ano, ao passo que CARVALHO et al. (1997) observaram aumento linear no consumo de EE e redução linear no de FDN com aumento do nível de concentrado na ração.

ARAÚJO et al. (1997), estudando várias proporções de volumoso: concentrado $(10: 90 ; 25: 75 ; 40: 60$; 55:45 e 90:10) na dieta de bezerros mestiços Holandês x Zebu, verificaram que os consumos de MS, $\mathrm{MO}, \mathrm{PB}, \mathrm{EE}, \mathrm{FDN}$ e NDT foram influenciados pelos níveis de volumoso na dieta.

A digestão realizada pelos animais ruminantes é o resultado líquido de uma seqüência de processos que ocorrem em diferentes segmentos do trato gastrointestinal. Nesta seqüência incluem a fermentação dos componentes dietéticos pelos microrganismos do rúmen-retículo, a hidrólise ácida e a degradação pelas enzimas do abomaso e intestino delgado do animal hospedeiro e a fermentação secundária no intestino grosso. Alguns fatores que influem na digestão são: o local, a natureza dos produtos finais absorvidos e a extensão dos nutrientes perdidos durante o processo (MERCHEN et al., 1997). Contudo, a composição em nutrientes da fração absorvida precisa ser compatível com a exigência nutricional do animal (COELHO DA SILVA e LEÃO, 1979).

As medidas de digestibilidade contribuem significativamente para o desenvolvimento de sistemas, para descrever e avaliar o potencial nutritivo dos alimentos (VAN SOEST, 1994). Existem muitos fatores que influenciam a digestibilidade, como composição dos alimentos, composição da ração, preparo dos alimentos e os fatores dependentes dos animais e do nível nutricional (McDONALD et al., 1993).

Uma das maneiras de se conseguir máximo consumo de energia é a manipulação na proporção de volumoso:concentrado. Mudando-se a ração de 100 para 50\% de volumoso, o consumo de MS aumenta em cerca de $35 \%$, observando-se também aumento da digestibilidade total da ração, refletindo a maior digestibilidade do concentrado. Por outro lado, há considerável decréscimo da digestibilidade da fibra, devido ao menor tempo de permanência do volumoso no trato digestivo. Essas informações sugerem que os efeitos favoráveis da adição de concentrado na dieta parecem ser curvilíneos e apresentam ponto ótimo, variando principalmente com a qualidade do volumoso (MATTOS, 1993). Contudo, ocorre aumento do consumo de MS, quando há acréscimo na digestibilidade da MS de 52 para $68 \%$, porém, acima de $68 \%$ de digestibilidade, a ingestão de MS está relacionada com o requerimento de energia do animal (ENSMINGER et al., 1990).

HUSSEIN et al. (1995), estudando os efeitos do nível de volumoso (70 e 30\%) nos consumos e na digestão aparente da MS, MO, FDN e EB, em novilhos mestiços (354 kg de peso vivo inicial), não verificaram efeito nos consumos de MS e MO, porém houve aumento no consumo de FDN para as dietas com $70 \%$ de volumoso. A digestibilidade aparente da MO diminuiu, quando os novilhos receberam dieta contendo $70 \%$ de volumoso, contudo, a digestão aparente de FDN e EB não foi influenciada pelos níveis de volumoso.

OKINE e MATHISON (1991) verificaram queda na digestão da MS, MO e FDN com aumento do nível de consumo. As digestibilidades da MS foram de 70,$5 ; 68,0 ; 65,0 ;$ e $60,2 \%$; da MO, 76,4; 73,7; 71,6; e $66,7 \%$; e da FDN, 60,$1 ; 58,6 ; 59,3$; e $57,1 \%$ para os níveis de consumo de mantença 1,$3 ; 1,5$; e 1,7 vezes a mantença, respectivamente.

BOURQUIN et al. (1994) estudaram os efeitos da proporção de volumoso:concentrado sobre o local e a extensão da digestão da MO, do nitrogênio total e dos componentes da parede celular do capim "Orchardgrass" (Dactylis glomerata), nos níveis de 60 e 96\% na dieta de novilhos mestiços. Esses autores verificaram aumento na digestibilidade aparente de MO $(68,7$ e $61,0 \%)$ e redução na de FDN $(52,3$ e $63,3 \%)$ em dieta com $60 \%$ de volumoso, entretanto, a do nitrogênio total $(54,3$ e 53,7\%) não foi influenciada pelos níveis de volumoso na dieta.

BERCHIELLI et al. (1994) verificaram maior consumo de MS nas dietas com baixa fibra e maior digestibilidade aparente da MS, MO e EB nas dietas com maiores níveis de concentrado. No entanto, não foram observados efeitos sobre a digestibilidade da FDN.

DUTRA et al. (1997) trabalharam com novilhos de predominância da raça Pardo Suíça, alimentados com dietas contendo baixa e alta fibra, em média, com 38,9 e $57,19 \%$ de FDN, respectivamente. Verificaram também maiores consumos de MS e MO nas rações de baixa fibra. A digestibilidade aparente de MS e MO foi maior nas rações com baixa fibra, contudo, a digestibilidade da FDN não foi influenciada pelos níveis de fibra na dieta.

RODRIGUEZ et al. (1997) verificaram maiores coeficientes de digestibilidade aparente de MS, MO, PB e EB com a elevação do nível de concentrado da 
172 Rev. bras. zootec.

ração. No entanto, não foi verificado efeito do nível de concentrado sobre a digestibilidade da FDN.

CARVALHO et al. (1997) observaram que os coeficientes de digestibilidade aparente da MS e MO aumentaram linearmente, entretanto, os de PB, EE e FDN não foram influenciados pelos níveis de concentrado da dieta.

ARAÚJO et al. (1997), estudando várias proporções de volumoso: concentrado (10:90; 25:75; 40:60; 55:45; e 90:10) na dieta de bezerros mestiços Holandês $\mathrm{x}$ Zebu, verificaram que a digestibilidade aparente de MS, MO, EE, CHO e EB decresceu, enquanto a da FDN aumentou linearmente com aumento do nível de volumoso da dieta.

As informações na literatura sobre a proporção adequada de volumoso e concentrado, na alimentação de bezerros da raça Holandesa destinados à produção de carne, ainda são muito escassas. Devido à grande importância da proporção com que nutrientes específicos influenciam a cinética ruminal, a eficiência de utilização dos nutrientes absorvidos e a economicidade da atividade, é fundamental o estudo eficaz da manipulação de dietas, para maximizar o desempenho produtivo e minimizar os custos no confinamento desses animais.

O objetivo deste trabalho foi avaliar o efeito de diferentes níveis de volumoso sobre os consumos e as digestibilidades aparentes de MS, MO, PB, EE, FDN, CHOT e EB e sobre os consumos de NDT, utilizando-se 35 bezerros da raça Holandesa puros por cruzamento, em confinamento.

\section{Material e Métodos}

Conduziu-se este experimento nas dependências do Laboratório Animal do Departamento de Zootecnia da Universidade Federal de Viçosa, no período de março de 1995 a julho de 1996.

Foram utilizados 35 bezerros da raça Holandesa puros por cruzamento, não-castrados, com idade média de 60 dias e peso vivo médio inicial de $78 \mathrm{~kg}$. Os animais foram confinados em baias individuais concretadas e cobertas com área de $8,0 \mathrm{~m}^{2}$, providas com comedouros e bebedouros.

Para a determinação do consumo e da digestibilidade aparente de matéria seca (MS), matéria orgânica $(\mathrm{MO})$, proteína bruta $(\mathrm{PB})$, extrato etéreo (EE), fibra em detergente neutro (FDN), carboidratos totais (CHOT) e energia bruta (EB) e do consumo de nutrientes digestíveis totais (NDT), foram formuladas quatro misturas concentradas à base de fubá de milho, farelo de soja, calcário e mistura mineral, com base nas exigências nutricionais, segundo as normas do NRC (1989), para ganho de peso esperado de 1,0 kg por dia.

Os ingredientes e as suas respectivas proporções para formulação dos concentrados e a composição química dos mesmos e do feno de capim coast-cross encontram-se na Tabela 1. Os teores de nutrientes das dietas contendo níveis crescentes de volumoso encontram-se na Tabela 2.

Antes de iniciar o período de adaptação de 15 dias, todos os animais foram devidamente identificados com brincos, pesados e tratados contra ecto e endoparasitos com produto à base de $1 \%$ de Ivermectin, na dosagem de $1 \mathrm{~mL} / 50 \mathrm{~kg}$ de peso vivo, e receberam ainda vitamina ADE injetável, na dosagem de $1 \mathrm{~mL} / 50 \mathrm{~kg}$ de peso vivo, ao início e a cada 60 dias de permanência no experimento.

Os animais foram pesados ao início do período experimental, ou seja, após o desaleitamento aos 60 dias de idade. Em seguida, foram submetidos a 15 dias de adaptação às instalações e dietas e pesados por dois dias consecutivos. No primeiro dia considerou-se peso vivo inicial e no segundo dia, após jejum de 16 horas, o peso inicial de jejum.

As dietas foram fornecidas, em refeição diária, às 7 h30 pela manhã, à vontade, durante todo o período experimental, ajustando-se sobra diária em torno de $10 \%$ do oferecido, por animal. Foram registradas diariamente as quantidades de dieta oferecida, das sobras para cada animal, e ainda realizadas amostragens semanais dos concentrados e do volumoso e diárias das sobras.

As estimativas dos coeficientes de digestibilidade aparentes totais de MS, MO, EE, PB, CHOT, FDN e EB foram obtidas a partir da realização de ensaios de digestibilidade, utilizando-se o óxido crômico $\left(\mathrm{Cr}_{2} \mathrm{O}_{3}\right)$ em pó, como indicador externo. Os ensaios foram realizados no segundo e quarto mês, a partir da data de entrada dos animais no experimento, ou seja, aos 120 e 180 dias de idade, aproximadamente. Foram fornecidos 5 gramas diárias do indicador, via oral, divididos em duas doses de 2,5 g, às 9 e 15 h, durante 16 dias, sendo 10 dias para estabilizar a excreção e seis dias para o período de coleta de fezes. As amostras fecais foram coletadas diretamente do reto, duas vezes ao dia, às 9 e $15 \mathrm{~h}$, sendo conservadas a $-5^{\circ} \mathrm{C}$. Ao final de cada período de coleta, as amostras individuais foram pré-secas e moídas em peneira de malha de $1 \mathrm{~mm}$ e originaram uma amostra composta por animal por período. Diariamente, durante o período de coleta, foram realizadas amostragens do feno 
Tabela 1 - Composição percentual dos ingredientes usados nos concentrados, na matéria natural e nos teores de matéria seca (MS), matéria orgânica (MO), proteína bruta (PB), extrato etéreo (EE), carboidratos totais (CHOT), fibra em detergente neutro (FDN), cálcio $(\mathrm{Ca})$, fósforo $(\mathrm{P})$, magnésio $(\mathrm{Mg})$, potássio $(\mathrm{K})$ e sódio $(\mathrm{Na})$ dos concentrados e do feno de capim coast-cross

Table 1 - Percent composition of feeds used in the concentrate and as fed basis and dry matter (DM), organic matter (OM), crude protein $(C P)$, ether extract (EE), total carbohydrates $(T C H)$, neutral detergent fiber (NDF), calcium (Ca), phosphorus $(P)$, magnesium $(M g)$, potassium $(K)$ and sodium (Na) of concentrates and coast-cross hay

\begin{tabular}{lccccc}
\hline Item & \multicolumn{4}{c}{ Concentrado (Concentrate) } & \multirow{2}{*}{ Feno (Hay) } \\
\cline { 2 - 5 } & 1 & 2 & 3 & 4 & \\
Ingrediente (Ingredient) & 82,77 & 77,29 & 68,67 & 54,31 & \\
Fubá de milho (Corn meal) & 17,23 & 22,71 & 31,33 & 45,69 & \\
Farelo de soja (Soybean meal) & & & & & \\
Composição (Composition) & 87,34 & 87,17 & 86,79 & 86,56 & 88,28 \\
MS $(D M), \%$ & 96,61 & 96,76 & 96,59 & 96,45 & 94,65 \\
$\mathrm{MO}(O M)^{1}$ & 16,65 & 18,74 & 21,17 & 26,37 & 6,94 \\
$\mathrm{~PB}(C P)^{1}$ & 3,22 & 3,48 & 3,76 & 2,84 & 1,13 \\
$\mathrm{EE}^{1}$ & 76,24 & 74,05 & 71,14 & 66,68 & 86,05 \\
$\mathrm{CHOT}(T C H)^{1}$ & 17,75 & 16,19 & 14,61 & 16,21 & 82,94 \\
$\mathrm{FDN}(N D F)^{1}$ & 0,55 & 0,54 & 0,60 & 0,73 & 0,41 \\
$\mathrm{Ca}^{1}$ & 0,20 & 0,21 & 0,31 & 0,30 & 0,16 \\
$\mathrm{P}^{1}$ & 0,11 & 0,12 & 0,14 & 0,15 & 0,12 \\
$\mathrm{Mg}^{1}$ & 0,83 & 0,84 & 0,98 & 1,11 & 1,72 \\
$\mathrm{~K}^{1}$ & 0,17 & 0,15 & 0,20 & 0,20 & 0,02 \\
$\mathrm{Na}^{1}$ & & & & &
\end{tabular}

$1 \%$ da MS (\% of DM).

Tabela 2 - Teores de matéria seca (MS), matéria orgânica $(\mathrm{MO})$, proteína bruta $(\mathrm{PB})$, extrato etéreo (EE), nutrientes digestíveis totais (NDT), carboidratos totais (CHOT), fibra em detergente neutro (FDN), cálcio $(\mathrm{Ca})$, fósforo $(\mathrm{P})$, magnésio $(\mathrm{Mg})$, potássio (K) e sódio $(\mathrm{Na})$

Table 2 - Dry matter (DM), organic matter (OM), crude protein $(C P)$, ether extract $(E E)$, total digestible nutrients $(T D N)$, total carbohydrates (TCH), neutral detergent fiber (NDF), calcium (Ca), phosphorus $(P)$, magnesium $(\mathrm{Mg})$, potassium $(\mathrm{K})$ and sodium $(\mathrm{Na})$ contents

\begin{tabular}{lcccc}
\hline Item & \multicolumn{4}{c}{ Nível de volumoso \% } \\
& 10 & 25 & 40 & 55 \\
\cline { 2 - 5 } & 87,43 & 87,45 & 87,39 & 87,51 \\
MS $(D M), \%$ & 96,41 & 96,23 & 95,81 & 95,46 \\
MO $(O M)^{1}$ & 15,68 & 15,79 & 15,48 & 15,68 \\
$\mathrm{~PB}^{1}(C P)^{1}$ & 3,01 & 2,89 & 2,71 & 1,90 \\
$\mathrm{EE}^{1}$ & 82,00 & 76,33 & 73,33 & 69,67 \\
$\mathrm{NDT}^{1}(T D N)^{1}$ & 77,20 & 77,05 & 77,10 & 77,33 \\
$\mathrm{CHOT}(T C H)^{1}$ & 24,27 & 32,88 & 41,94 & 52,91 \\
$\mathrm{FDN}^{1}(N D F)^{1}$ & 0,54 & 0,51 & 0,52 & 0,55 \\
$\mathrm{Ca}^{1}$ & 0,20 & 0,20 & 0,25 & 0,22 \\
$\mathrm{P}^{1}$ & 0,11 & 0,12 & 0,13 & 0,13 \\
$\mathrm{Mg}^{1}$ & 0,92 & 1,06 & 1,28 & 1,45 \\
$\mathrm{~K}^{1}$ & 0,16 & 0,12 & 0,13 & 0,10 \\
$\mathrm{Na}^{1}$ & \multicolumn{4}{c}{. }
\end{tabular}

$1 \%$ da MS (\% of DM) e do concentrado oferecidos, bem como das sobras de cada animal. Após a amostragem, o material foi acondicionado em vidros, identificados e armazenados em congelador para análises posteriores.

Para o cálculo do consumo de nutrientes digestíveis totais (cNDT), foi empregada a fórmula proposta por SNIFFEN et al. (1992), em que o $\mathrm{cNDT}=(\mathrm{cPB}-$ PBf $)+2,25$ (cEE - EEf) + (cCHOT - CHOTf $)$, em que $\mathrm{cPB}$, cEE e cCHOT significam, respectivamente, consumos de PB, EE e CHOT e PBf, EEf e CHOTf, excreções fecais de PB, EE e CHOT.

Os carboidratos totais (CHOT) foram obtidos pela diferença de $100-(\% \mathrm{~PB}+\% \mathrm{EE}+\%$ Cinzas $)$, segundo SNIFFEN et al. (1992).

As determinações de MS, MO, FDN, EE, EB e nitrogênio total dos alimentos e das fezes foram feitas conforme SILVA (1990), ao passo que as concentrações de cromo nas amostras fecais (Willians e colaboradores, em 1962, citados por SILVA, 1990) e os cálculos dos fluxos de matéria seca fecal foram realizados conforme COELHO DA SILVA e LEÃO (1979). 
174 Rev. bras. zootec.

Utilizou-se delineamento inteiramente casualizado, com quatro tratamentos e nove repetições, exceto o primeiro tratamento, que continha oito repetições. As análises estatísticas das variáveis estudadas foram interpretadas por análises de variância e regressão, utilizando-se o programa computacional SAEG. Os coeficientes de regressão foram comparados pelo teste "t" a 1 e $5 \%$ de probabilidade.

\section{Resultados e Discussão}

Os resultados referentes aos consumos médios diários de MS, MO e FDN, em kg/animal, \% PV e g/ $\mathrm{kg}^{0,75}$, são mostrados na Tabela 3 .

Os consumos médios de MS e MO, em kg/dia, \% $\mathrm{PV}$ e $\mathrm{g} / \mathrm{kg}^{0,75}$, não foram influenciados pelos níveis de volumoso na dieta.

Inúmeros trabalhos na literatura relataram a influência de diferentes níveis de volumoso sobre os consumos de MS e MO (GONÇALVES, 1988; ANDRADE, 1992; BERCHIELLI, et al., 1994; RODRIGUEZ et al., 1996; ARAÚJO et al., 1997; FERREIRA, 1997; e TIBO et al., 1997). Por outro lado, HUSSEIN et al. (1995) e CARVALHO et al. (1997) não verificaram efeito de diferentes proporções volumoso: concentrado sobre os consumos de MS e MO.

O consumo médio de FDN, em $\mathrm{kg} / \mathrm{dia}$, \% PV e g/ $\mathrm{kg}^{0,75}$, aumentou linearmente $(\mathrm{P}<0,01)$ com adição de volumoso na dieta, o que pode ser explicado pelo aumento da concentração de FDN nas rações, quando se aumentaram os níveis de volumoso na dieta.
O NRC (1989), para bovino leiteiro, recomendou ingestão ótima de FDN de 1,2 $\pm 0,1 \% \mathrm{PV}$, valor acima do encontrado para os níveis de 10, 25, 40 e $55 \%$ de volumoso nas dietas neste estudo, que variou de 0,47 a $0,93 \%$ PV (Tabela 3 ).

HUSSEIN et al. (1995), ARAÚJO et al. (1997), CARVALHO et al. (1997) e FERREIRA (1997) verificaram efeito linear crescente no consumo de FDN (kg/dia e \% PV) em dietas com diferentes proporções volumoso:concentrado. Por outro lado, RODRIGUEZ et al. (1996) não encontraram efeitos dos níveis de concentrado sobre o consumo de FDN $\left(\mathrm{g} / \mathrm{kg}^{0,75}\right.$ e \% PV).

Os consumos de PB, EE, CHOT e NDT, em kg/ dia e \% PV, e seus respectivos coeficientes de variação e as equações de regressão ajustadas são mostrados na Tabela 4. O consumo de PB, quando expresso em $\mathrm{kg} / \mathrm{dia}$ ou \% $\mathrm{PV}$, não foi influenciado pelos níveis de volumoso na dieta. ARAÚJO et al. (1997) verificaram comportamento quadrático, sendo o consumo máximo de PB estimado com 43,30\% de volumoso na dieta. Já RODRIGUEZ et al. (1996) e FERREIRA (1997) observaram redução linear no consumo de PB com aumento do nível de concentrado na dieta.

O valor para consumo médio de $\mathrm{PB}$ ( $\mathrm{kg} / \mathrm{dia})$ foi $7,12 \%$ inferior do recomendado pelo NRC (1989) para macho não-castrado, de grande porte e com $200 \mathrm{~kg}$ de peso vivo, e suficiente para atender ganho de peso de, aproximadamente, $1,0 \mathrm{~kg} / \mathrm{dia}$.

O consumo de EE, em $\mathrm{kg} / \mathrm{dia}$ ou \% PV, decresceu linearmente $(\mathrm{P}<0,01)$ em função dos níveis crescen-

Tabela 3 -Médias, equações de regressão ajustadas (ER) para os consumos diários de matéria seca (MS), matéria orgânica (MO) e fibra em detergente neutro (FDN)

Table 3 - Means, fitted regression equations (RE) for the daily intake of dry matter (DM), organic matter (OM) and neutral detergent fiber $(N D F)$

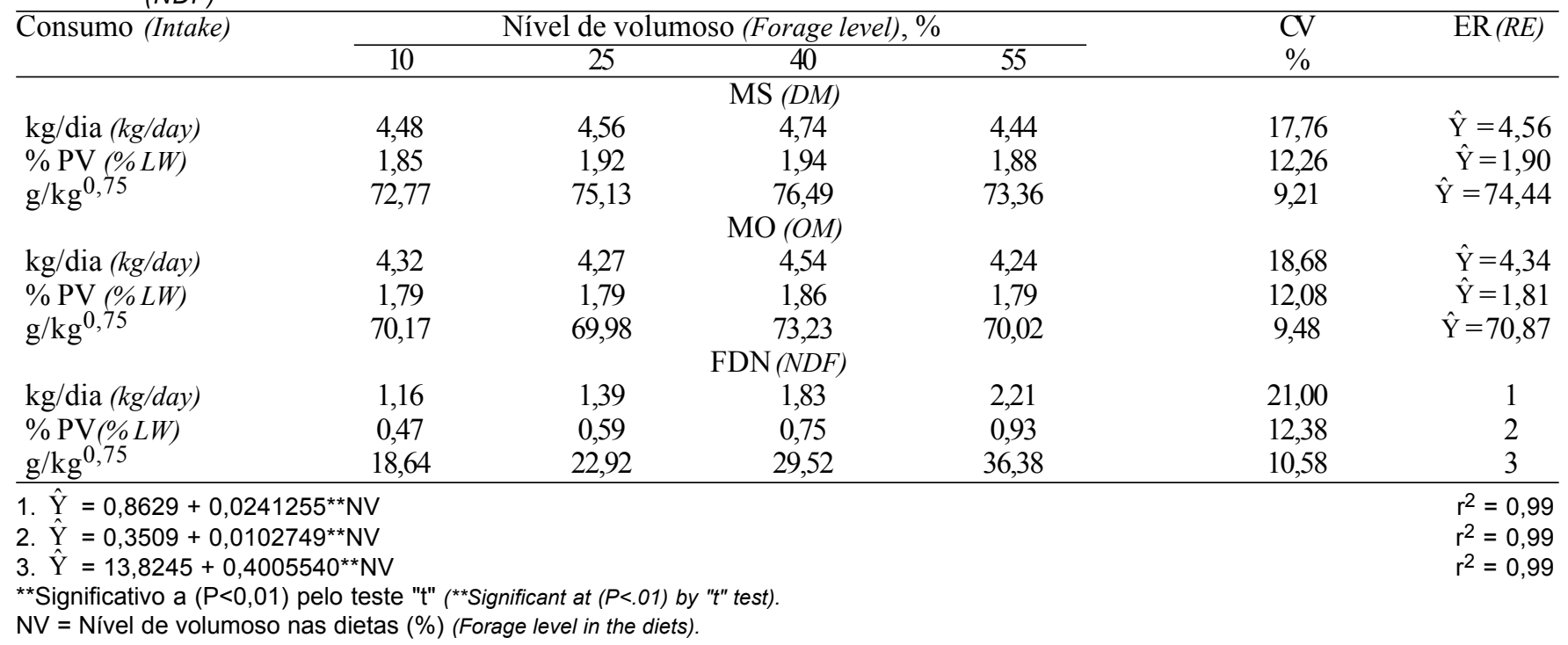


SIGNORETTI et al.

Tabela 4 - Médias e equações de regressão ajustadas (ER) para os consumos de proteína bruta (PB), extrato etéreo (EE), carboidratos totais (CHOT) e nutrientes digestíveis totais (NDT)

Table 4 - Means and fitted regression equations (RE) for the intake of crude protein (CP), ether extract (EE), total carbohydrates (TCH) and total digestible nutrients (TDN)

\begin{tabular}{|c|c|c|c|c|c|c|}
\hline \multirow[t]{2}{*}{ Item } & \multicolumn{4}{|c|}{ Nível de volumoso (Forage level), \% } & \multirow{2}{*}{$\begin{array}{l}\mathrm{CV} \\
\%\end{array}$} & \multirow[t]{2}{*}{$\mathrm{ER}(R E)$} \\
\hline & 10 & 25 & 40 & 55 & & \\
\hline \multicolumn{7}{|c|}{$\mathrm{kg} / \mathrm{dia}(\mathrm{kg} /$ day $)$} \\
\hline $\mathrm{PB}(C P)$ & 0,70 & 0,73 & 0,76 & 0,73 & 17,53 & $\hat{\mathrm{Y}}=0,73$ \\
\hline $\mathrm{EE}$ & 0,14 & 0,14 & 0,13 & 0,09 & 17,43 & 1 \\
\hline $\mathrm{CHOT}(T C H)$ & 3,47 & 3,51 & 3,62 & 3,40 & 17,80 & $\hat{\mathrm{Y}}=3,50$ \\
\hline $\operatorname{NDT}(T D N)$ & 3,68 & 3,49 & 3,47 & 3,10 & 17,66 & 2 \\
\hline \multicolumn{7}{|c|}{$\% \mathrm{PV}(\% L W)$} \\
\hline $\mathrm{PB}(C P)$ & 0,29 & 0,31 & 0,31 & 0,31 & 11,80 & $\hat{\mathrm{Y}}=0,31$ \\
\hline $\mathrm{EE}$ & 0,06 & 0,06 & 0,06 & 0,04 & 12,12 & 3 \\
\hline $\mathrm{CHOT}(\mathrm{TCH})$ & 1,43 & 1,48 & 1,49 & 1,44 & 12,35 & $\hat{\mathrm{Y}}=1,46$ \\
\hline $\operatorname{NDT}(T D N)$ & 1,52 & 1,47 & 1,43 & 1,31 & 12,42 & 4 \\
\hline \multirow{5}{*}{\multicolumn{5}{|c|}{ 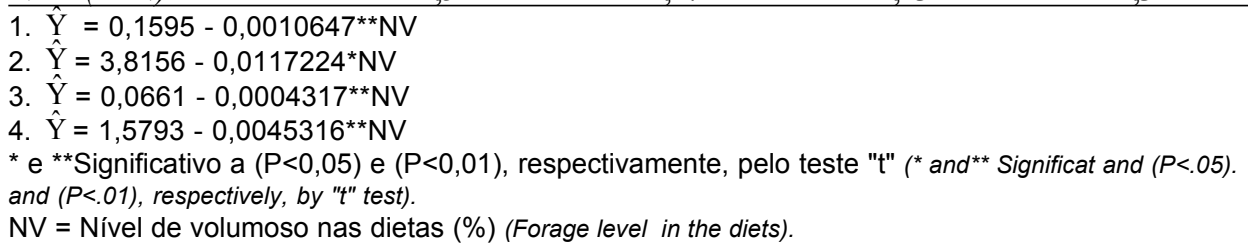 }} & & $r^{2}=0,66$ \\
\hline & & & & & & $r^{2}=0,86$ \\
\hline & & & & & & $r^{2}=0,67$ \\
\hline & & & & & & $r^{2}=0,94$ \\
\hline & & & & & & \\
\hline
\end{tabular}

tes de volumoso na dieta. A redução observada pode ser explicada pelo declínio na concentração de EE das dietas com maiores níveis de volumoso. ARAÚJO et al. (1997), CARVALHO et al. (1997) e FERREIRA (1997) verificaram comportamento similar, em dietas de bovinos em crescimento, contendo diferentes relações volumoso: concentrado.

O consumo de CHOT, em kg/dia ou \% PV, não foi influenciado pelos níveis de volumoso na dieta. ARAÚJO et al. (1997), CARVALHO et al. (1997) e FERREIRA (1997) não observaram efeitos de diferentes proporções volumoso:concentrado sobre o consumo de CHOT, em kg/dia.

O consumo de NDT, em $\mathrm{kg} / \mathrm{dia}$ ou $\% \mathrm{PV}$, decresceu linearmente $(\mathrm{P}<0,01)$, à medida que se aumentou o nível de volumoso na dieta, o que pode ser explicado pela redução do teor de NDT nas dietas com aumento da participação de volumoso. Comportamento semelhante foi encontrado por FERREIRA (1997).

Segundo o NRC (1989), o requerimento de NDT para bovino de grande porte, não-castrado, pesando $200 \mathrm{~kg}$ e ganhando diariamente $1,0 \mathrm{~kg}$, é de $3,34 \mathrm{~kg} / \mathrm{dia}$, valor que está próximo ao encontrado neste trabalho.

Foram conduzidos dois ensaios de digestibilidade durante o período experimental, contudo, não foram observadas diferenças entre os mesmos, optando-sepela utilização dos coeficientes de digestibilidade médios.

Os coeficientes de digestibilidade aparentes de MS, MO, PB, EE, FDN, CHOT e EB, com seus respectivos coeficientes de variação e suas equações de regressão ajustadas, encontram-se na Tabela 5. Com exceção da FDN, as demais digestibilidades diminuíram com au- mento de volumoso nas dietas.

A digestibilidade aparente da MS variou de 70,69 a 81,45 \% para maior e menor nível de participação de volumoso, respectivamente. Comportamentos semelhantes foram relatados por RODE et al. (1985), BERCHIELLI et al. (1994), ARAÚJO et al. (1997), CARVALHO et al. (1997), RODRIGUEZ et al. (1997) e TIBO et al. (1997), para digestibilidade aparente da MS e MO, e BOURQUIN et al. (1994) e HUSSEIN et al. (1995), para digestibilidade aparente da MO.

DUTRA et al. (1997) verificaram aumento na digestibilidade aparente da MS (52,23 e 38,71\%) e MO $(54,73$ e $42,02 \%)$ nas rações com baixo teor de fibra $(38,90 \%$ de FDN). Esses resultados são semelhantes aos encontrados neste trabalho, pois, à medida que os teores de FDN das dietas aumentaram $(24,27 ; 32,88$; 41,94; e 52,91\%), para os respectivos níveis crescentes de volumoso $(10,25,40$ e 55\%), ocorreu redução da digestibilidade aparente da MS.

Houve efeito linear $(\mathrm{P}<0,01)$ decrescente para os coeficientes de digestibilidade da $\mathrm{PB}$, em função dos níveis crescentes de volumoso nas dietas. Resultados semelhantes foram relatados por LUCCI et al. (1989) e RODRIGUEZ et al. (1997). Por outro lado, ARAÚJO et al. (1997) verificaram efeito quadrático, utilizando no estudo os mesmos níveis de volumoso do presente trabalho. Já BOURQUIN et al. (1994) e CARVALHO et al.(1997) não verificaram efeito de diferentes relações volumoso:concentrado sobre a digestibilidade da $\mathrm{PB}$.

Ocorreu redução linear $(\mathrm{P}<0,01)$ no coeficiente de digestibilidade aparente do EE e da EB, em função dos níveis crescentes de volumoso, possivelmente em 
176 Rev. bras. zootec.

Tabela 5 - Médias e equações de regressão ajustadas (ER) para as digestibilidades aparentes totais de matéria seca (MS), matéria orgânica $(\mathrm{MO})$, proteína bruta $(\mathrm{PB})$, extrato etéreo (EE), fibra em detergente neutro (FDN), carboidratos totais (CHOT) e energia bruta (EB)

Table 5 - Means and fitted regression equations (RE) for the total apparent digestibility of dry matter (DM), organic matter (OM), crude protein $(C P)$, ether extract (EE), neutral detergent fiber (NDF), total carbohydrates (TCH) and gross energy (GE)

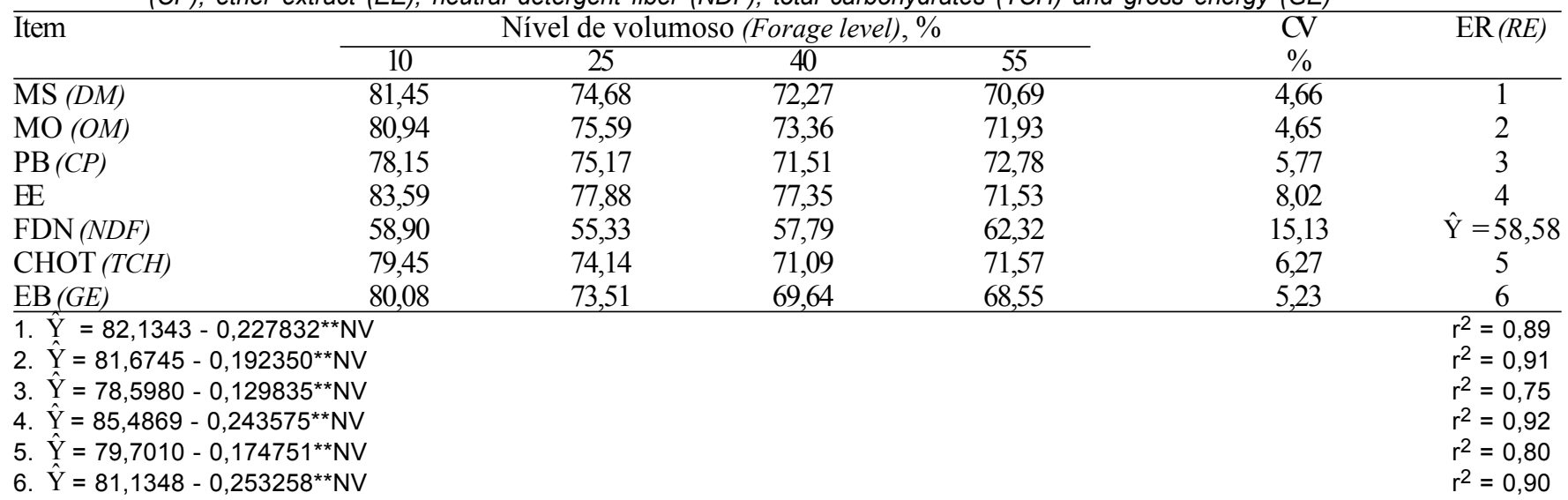

**Significativo a $(P<0,01)$ pelo teste "t" (**Significant at $(P<.01)$ by "t:"test).

$\mathrm{NV}=$ Nível de volumoso nas dietas (\%) (Forage level in the diets).

virtude do menor teor de EE das dietas com maiores níveis de volumoso. Comportamentos similares foram observados por ARAÚJO et al. (1997) e RODRIGUEZ et al. (1997). No entanto, não foram verificados efeitos de diferentes proporções de volumoso:concentrado sobre a digestibilidade do EE (HUSSEIN et al., 1995; CARVALHO et al.,1997) e da EB (BERCHIELLI et al., 1994).

A digestibilidade aparente dos $\mathrm{CHOT}$ decresceu linearmente $(\mathrm{P}<0,01)$, em função dos níveis de volumoso na dieta, o que ocorreu, provavelmente, devido à maior concentração de carboidratos não-estruturais das dietas com menor nível de volumoso. Resultados semelhantes foram encontrados por VALADARES FILHO (1985) e ARAÚJO et al. (1997).

Os coeficientes de digestibilidade aparente da FDN não foram influenciados pelos níveis de volumoso nas dietas. BERCHIELLI et al. (1994), HUSSEIN et al. (1995), CARVALHO et al. (1997), DUTRA et al. (1997) e RODRIGUEZ et al. (1997) observaram comportamentos similares em dietas com diferentes proporções de volumoso:concentrado. LUCCI et al. (1989), OLIVEIRA et al. (1991), BOURQUIN et al. (1994) e ARAÚJO et al. (1997), entretanto, verificaram efeitos de várias relações volumoso:concentrado na ração sobre a digestibilidade aparente da FDN.

\section{Conclusões}

Os consumos de MS e MO, em kg/dia, \% PV e g/ $\mathrm{kg}^{0,75}$, e os de PB e CHOT, em kg/dia ou \% PV, não foram influenciados pelos níveis de volumoso nas dietas.
O consumo de FDN, em $\mathrm{kg} / \mathrm{dia}, \% \mathrm{PV}$ e $\mathrm{g} / \mathrm{kg}^{0,75}$, aumentou, enquanto o de EE e NDT, em $\mathrm{kg} /$ dia ou \% $\mathrm{PV}$, decresceu linearmente com o aumento da participação do feno de capim coast-cross na dieta.

Os coeficientes de digestibilidade aparentes de MS, MO, PB, EE, CHOT e EB decresceram linearmente com o aumento do nível de inclusão de volumoso nas dietas.

O coeficiente de digestibilidade aparente da FDN não foi influenciado pelos níveis de volumoso nas dietas, encontrando-se valor médio de 58,58\%.

\section{Referências Bibliográficas}

AGRICULTURAL RESEARCH COUNCIL - ARC. 1980. The nutrients requirements of ruminants livestock. London: Commonwealth Agricultural Bureaux. 351p.

ALLEN, M.S. 1996. Physical constraints on voluntary intake of forage by ruminants. J. Anim. Sci., 74(12):3063 - 3075.

ANDRADE, A.T. Digestão total e parcial da matéria seca, matéria orgânica, energia bruta e proteína bruta em diferentes grupos genéticos de bovídeos. Viçosa, MG: UFV, 1992. $181 \mathrm{p}$. Tese (Doutorado em Zootecnia) - Universidade Federal de Viçosa, 1992.

ARAÚJO, G.G.L., COELHO DA SILVA, J.F., VALADARES FILHO, S.C. et al. Consumo e digestibilidade total dos nutrientes de dietas contendo diferentes níveis de volumoso, em bezerros. In: REUNIÃO ANUAL DA SOCIEDADE BRASILEIRA DE ZOOTECNIA, 34, Juiz de Fora, MG, 1997. Anais... Juiz de Fora: SBZ, 1997. p.234 -236.

BERCHIELLI, T.T., RODRIGUEZ, N.M., OLIVEIRA, H.P. et al. Ingestão, digestibilidade aparente total e partição da digestão em função de níveis crescentes de concentrado na dieta. In: REUNIÃO ANUAL DA SOCIEDADE BRASILEIRA DE ZOOTECNIA, 31, Maringá, PR, 1994. Anais... Maringá: SBZ, 1994. p.489. 
BOURQUIN, L.D., TITGEMEYER, E.C., MERCHEN, N.R. et al. 1994. Forage level and particle size effects on orchardgrass digestion by steers. I. Site and extent of organic matter, $\mathrm{N}$ and cell wall digestion. J. Anim. Sci., 72:746 - 758.

CARVALHO, A.U., VALADARES FILHO, S.C., COELHO DA SILVA, J.F. et al. 1997. Níveis de concentrado em dietas de zebuínos. 1. Consumo e digestibilidade aparente. R. Bras. Zootec., 26(5):986 -995.

COELHO DA SILVA, J.F., LEÃO, M.I. 1979. Fundamentos de nutrição dos ruminantes. Piracicaba:Livroceres. 380p.

DUTRA, A.R.D., QUEIROZ, A.C., PEREIRA, J.C. et al. 1997. Efeitos dos níveis de fibra e das fontes de proteína sobre o consumo e digestão dos nutrientes em novilhos. R. Bras. Zootec., 26(4):787 - 796.

ENSMINGER, M.E., OLDFIELD, J.E., HEINEMANN, W.W. 1990. Feeds \& Nutrition. 2.ed. Davis, California: The Ensminger Publishing. 1544p.

FERREIRA, M.A. Desempenho, exigências nutricionais e eficiência de utilização da energia metabolizável para ganho de peso de bovinos $F_{1}$ Simental x Nelore. Viçosa, MG:UFV, 1997. 97p. Tese (Doutorado em Zootecnia) - Universidade Federal de Viçosa, 1997.

FLUHARTY, F.L., LOERCH, S.C., SMITH, F.E. 1994. Effects of energy density and protein source on diet digestibility and performance of calves after arrival at the feedlot. J. Anim. Sci., $72: 1616-1622$.

FORBES, J.M. 1996. Integration of regulatory signals controlling forage intake in ruminants. J. Anim. Sci., 74(12):3029-3035.

GILL, M., THIAGO, L.R.S., BUCHANAM-SMITH, J.G. 1987. Intake problems associated with ensiled forages. In: FEED INTAKE BY BEEF CATTLE SYMPOSIUM. Proceedings.. Oklahoma: Oklahoma State University. p. 341-352.

GONÇALVES, L.C. Digestibilidade, composição corporal, exigências nutricionais e características de carcaças de zebuinos, taurinos e bubalinos. Viçosa, MG:UFV, 1988, 238 p. Tese (Doutorado em Zootecnia) - Universidade Federal de Viçosa, 1988.

HUSSEIN, H.S., MERCHEN, N.R., FAHEY JR., G.C. 1995. Effects of forage level and canola seed supplementation on site and extent of digestion of organic matter, carbohydrates, and energy by steers. J. Anim. Sci., 73:2458-2468.

ILLIUS, A.W., JESSOP, N.S. 1996. Metabolic constraints on voluntary intake in ruminants. J. Anim. Sci., 74(12): 3052-3062.

LUCCI, C.S., NOGUEIRA FILHO, J.C.M., HERLING, V.R. et al. 1989. Fenos de capim de Rhodes (Chloris gayana) ou de alfafa (Medicago sativa) para bezerros, em dietas com dois níveis protéicos. I. Digestibilidade. R. Fac. Med. Vet.Zootec., 26(2):259-266.

MATTOS, W.R.S. 1993. Nutrição para performance máxima In: PEIXOTO, A.M. (Ed). Nutrição de bovinos: conceitos básicos e aplicados. Piracicaba:FEALQ. p.209-222.

McDONALD, P., EDWARDS, R., GREENHALGH, J.F.D. 1993. Nutrition animal. 4. ed. Zaragoza:Acríbia. 571p.

MERCHEN, N.R., ELIZALDE, J.C., DRACHLEY, J.K. 1997. Current perspective on assessing site of digestion in ruminants. J. Anim. Sci., 75(8):2223-2234.

MERTENS, D.R. Análise da fibra e sua utilização na avaliação e formulação de rações. In: SIMPÓSIO INTERNACIONAL DE RUMINANTES, REUNIÃO ANUAL DA SOCIEDADE BRASILEIRA DE ZOOTECNIA, 29, Lavras, MG, 1992. Anais... Lavras: SBZ, 1992. p.188-219.

MERTENS, D.R. 1994. Regulation of forage intake. In: FAHEY, J.F.G.C. (Ed). Forage quality evaluation and utilization. Madison: American Society of Agronomy, Inc., Crop Science Society of America, Inc., Soil Science of America, Inc., Wisconsin, USA. p.450-493.
NATIONAL RESEARCH COUNCIL - NRC. 1989. Nutrient requirements of dairy cattle. 6.ed. Washington, D.C. 157 p.

NOLLER, C.H., NASCIMENTO JR., D., QUEIROZ, D.S. Determinando as exigências nutricionais de animais em pastejo. In: SIMPÓSIO SOBRE MANEJO DE PASTAGENS, 13, Piracicaba, SP, 1996. Anais... Piracicaba: FEALQ, 1996.

OKINE, E.K., MATHISON, G.W. 1991. Effects of feed intake on particle distribuition passage of digesta, and extent of digestion in the gastrointestinal tract of cattle. J. Anim. Sci., 69:3435-3445.

OLIVEIRA, R.F.M., FONTES, C.A.A, GOMIDE, J.A. et al.1991. Estudo das recuperação fecal de $\mathrm{Cr}_{2} \mathrm{O}_{3}$ e dos indicadores internos cia, cida e lignina em períodos de coleta de dois a sete dias, em bovinos. R. Soc. Bras. Zootec., 20(5):522-531.

RODE, M.L., WEAKLEY, D.C., SATTER, L.D. 1985. Effects of forage amount and particle size in diets of lactating dairy cows on site of digestion and microbial protein synthesis. Can. J. Anim, Sci., 65(1):101-111.

RODRIGUEZ, L.R.R., FONTES, C.A.A., JORGE, A.M. et al. 1996. Consumo de rações contendo quatro níveis de concentrado por bovinos holandeses e nelores e por bubalinos. $R$. Soc. Bras. Zootec., 25(3):568-581.

RODRIGUEZ, L.R.R., FONTES, C.A.A., JORGE, A.M. et al. 1997. Digestibilidade de rações contendo quatro níveis de concentrado, em bovinos (Taurinos, Zebuínos) e Bubalinos. R. Bras. Zootec., 26(4):844-851.

SILVA, D.J. 1990. Análise de alimentos (Métodos químicos e biológicos). Viçosa, MG: UFV. 196p.

SNIFFEN, C.J., O'CONNOR, J.D., VAN SOEST, P.J. et al. 1992. A net carbohydrate and protein system for evaluating cattle diets. II. Carbohydrate and protein availability. J. Anim. Sci., 70:3562-3577.

THIAGO, L.R.S., GILL, M. Consumo voluntário de forragens por ruminantes: mecanismo físico ou fisiológico? In: SIMPÓSIO SOBRE PRODUÇÃO ANIMAL, 7, Campinas, SP, 1990. Anais... Piracicaba: FEALQ, 1990. p.77-107.

TIBO, G.C., VALADARES FILHO, S.C., COELHO DA SILVA, J.F. et al. Consumo, digestibilidade e metodologias de coleta de amostras de digestas em novilhos alimentados com vários níveis de concentrado. In: REUNIÃO ANUAL DA SOCIEDADE BRASILEIRA DE ZOOTECNIA, 34, 1997, Juiz de Fora, MG, 1997. Anais... Juiz de Fora: SBZ, 1997.

VALADARES FILHO, S.C. Digestão total e parcial da matéria seca e carboidratos em bovinos e bubalinos. Viçosa, MG:UFV, 1985. 148p. Tese (Doutorado em Zootecnia) - Universidade Federal de Viçosa, 1985.

VAN SOEST, P.J. 1994. Nutritional ecology of the ruminant. 2. ed. London:Constock Publishing Associates, USA. 476p.

VAN SOEST, P.J. 1965. Symposium on factors influencing the voluntary intake in relation to chemical composition and digestibility. J. Anim. Sci., 24(2):834-843.
Recebido em: 08/04/98 Aceito em: 20/08/98 